OPEN

SUBJECT AREAS:

ATTRIBUTION

ATMOSPHERIC DYNAMICS

Received

31 July 2013

Accepted

18 September 2013

Published

21 October 2013

Correspondence and requests for materials should be addressed to K.A. lashok@tropmet. res.in)

\section{Falling monsoon depression frequency: A Gray-Sikka conditions perspective}

\author{
A. G. Prajeesh' ', K. Ashok' \& D. V. Bhaskar Rao²
}

${ }^{1}$ Indian Institute of Tropical Meteorology, Pune, India, ${ }^{2}$ Jackson State University, USA.

In this study, we show that the annual monsoon depression (MD) frequency making landfall on the east coast of India shows a statistically significant decreasing trend for the period 1979-2010. Importantly, about $80 \%$ of this fall is confined to the south of $20^{\circ} \mathrm{N}$. To understand the plausible reason(s) for the weakening frequency of MDs in the southern Bay of Bengal in recent decades, we examine some of the seasonal average in-situ atmospheric parameters important for tropical cyclogenesis; we use various observational data from the IMD, and three atmospheric climate reanalysis datasets to account for possible quality constraints in them. Our findings suggest that the observed weakening of MD frequency south of $20^{\circ} \mathrm{N}$ in the Bay of Bengal since 1950s is likely due to a declining trend in the mid-tropospheric relative humidity over the Indian region. Our numerical sensitivity experiments support this finding.

M onsoon depressions (MDs) in the Bay of Bengal (BoB) are the most important synoptic scale transient disturbance associated with the Indian summer monsoon (June through September; henceforth JJAS), and contribute about $10 \%$ of the seasonal rainfall ${ }^{1}$. The observed long term average number of depressions per year is roughly $7 \sim 8^{2}$.

A good number of MDs forming in BoB originate as low-pressure disturbances that come from the western Pacific Ocean and the South China Sea ${ }^{3-6}$. The horizontal scale of a typical MD is around $1500 \mathrm{~km}$, and they vertically extend up to a height of $8 \mathrm{~km}^{1}$. After the formation, they generally move westward with a typical zonal speed of about $5 \%$ day, and have a life cycle of about 3 to 5 days. These systems generally have two or three closed isobars with $2 \mathrm{hPa}$ intervals. Heavy rainfall crossing even $300 \mathrm{~mm} /$ day is the most distinguishable phenomenon associated with these disturbances. Horizontal wind speeds of $7.5(20) \mathrm{m} / \mathrm{s}$ at the surface $(850 \mathrm{hPa})$ are noted, and the strongest winds, cloudiness and precipitation are found to be the maximum in the southwest sector of the storm $^{7}$. The relative vorticity has a maximum value of the order of $5 \times 10^{-5} \mathrm{~s}^{-1}\left(12 \times 10^{-5} \mathrm{~s}^{-1}\right)$ at the surface $(800 \mathrm{hPa})^{1,8}$. These disturbances have a cold core in the lower troposphere which is maintained by the evaporation of the falling rain and the adiabatic ascent ${ }^{7,8}$; a weak warm core structure sits over this cold core, maintained by latent heat release ${ }^{54}$.

Studies such as Sikka ${ }^{9}$, Mooley \& Shukla ${ }^{10}$, Jadhav ${ }^{11}$, Krishnamurthy \& Ajayamohan ${ }^{12}$ etc. have reported that there exists a marked relationship between central Indian monsoon rainfall and low pressure systems (LPS) in their totality, i.e., covering the Low Pressure Areas and MDs. However, some of these studies suggest that there is no significant relationship between the annual frequency/longevity of the MDs with seasonal monsoon rainfall. Notwithstanding this, rainfall from MDs is a significant contributor to seasonal rainfall in some part of the east coast of India, and importantly, can cause severe floods associated with extreme rainfall ${ }^{13,14}$. Therefore, any changes in MD frequency, intensity, and tracks have relevance for the floods and hydrology of various rivers/ river basins. Understanding any such long term changes is therefore important for hydrological planning and management in these parts.

Recent studies report a negative trend in the frequency of MD since $1950 \mathrm{~s}^{2,15-17}$, in spite of increasing SST over BoB. Rajeevan et al. ${ }^{2}$, Kumar \& Dash ${ }^{18}$ and Jadhav \& Munot $^{17}$ show that the decreasing frequency in the number of MD is significantly coincident with increasing number of Low Pressure Areas during the same season. Importantly, recent studies do not find any such decreasing trend in the cyclonic activity in west north Pacific ${ }^{19,20}$. From these, it can be concluded that some background atmospheric and oceanic in situ conditions in the BoB are possibly limiting the intensification of low pressure areas into MDs.

According to $\mathrm{Gray}^{21}$, the essential environmental parameters for tropical cyclogenesis are:

(1) Large values of low-level relative vorticity (at $\sim 950 \mathrm{hPa}$ ), 
(3) Low values of vertical shear of horizontal winds between 950 and $200 \mathrm{hPa}$. Low values of vertical shear enable the condensational warming to be concentrated over moving disturbance. The high vertical shear during the monsoon season is a reason why the MDs do not strengthen further as tropical storms

(4) Large values of ocean thermal energy;

(5) Large values of surface to mid-tropospheric equivalent potential temperature gradient, which is essential for cumulus convection, and

(6) Large values of mid-tropospheric humidity (average of $500 \mathrm{hPa}$ to $700 \mathrm{hPa}$ ), essential for deep cumulus convection and high rainfall efficiency.

Sikka ${ }^{1}$ has also identified the high Sea Surface temperature (SST), presence of low-level cyclonic vorticity in North BoB, high midtroposphere (henceforth MT) humidity and weak vertical wind shear, as the necessary conditions, in agreement with those of Gray ${ }^{21}$.

Rao et al. ${ }^{22}$ suggest the weakening vertical shear of the easterly jet stream in recent decades as a possible reason for decrease in the frequency of $\mathrm{MD}$, as such as condition is tantamount to a weakening in baroclinic instability. However, the relative importance of barotropic vs. baroclinic instability for the monsoon depressions is not yet clear $^{23-25}$. Further, as far as the in situ conditions are concerned, as per $\mathrm{Gray}^{21}$, any decrease in vertical wind shear should rather favor the intensification of cyclonic systems in tropics due to a reduction in the ventilation effect. Interestingly, Kumar \& Sankar ${ }^{26}$ cite, along with several other parameters, a weakening MT relative humidity $(\mathrm{RH})$ as a potential factor for a weakening trend in synoptic disturbances in the BoB. Therefore, in this paper, we carry out a simultaneous and detailed analysis of the reanalyzed climate datasets for the period of 1950-2010 to identify whether there have been any significant decadal changes in various Gray-Sikka parameters that are favorable for tropical cyclogenesis, and if so whether such changes can be the cause behind the observed decrease in MD frequency. We also examine whether the fall of the MD frequency is uniform along the east coast of India. Given that the moisture reanalysis products in the presatellite period may be subject to quality limitations, we verify our analysis with multiple reanalysis data sets as necessary. We also report results from various numerical sensitivity experiments we carried out using an axi-symmetric tropical cyclone model, to confirm our findings.

\section{Results}

Decadal changes in the MD frequency: a Gray-Sikka condition perspective. A time series of seasonal frequency of the MDs, and for the period of 1891 to 2010 clearly shows (Figure 1a) a decreasing trend in the frequency after 1950s, which is significant at $99 \%$ confidence level (Mann-Kendall test). After 1985, the mean frequency of MD reduces to 2-3 depression/season. On the other hand, we also find a significant increasing trend in the JJAS mean SST, averaged over BoB since 1950s (figure S1.b [Supplementary Information]), in agreement with the previous studies ${ }^{2,17}$; this rules out the role of the SST in the falling frequency of the MDs. We have also verified that the area-averaged vertical wind shear (difference in the zonal winds at $850 \mathrm{hPa}$ and $200 \mathrm{hPa}$ ) and the low level relative vorticity in the region does neither exhibit a significant trend for the period 1950-2010 (Figure S2) nor its the correlation between with the frequency of the MD significant.

A time series of the NCEP/NCAR reanalyzed MT RH over the BoB and adjoining land region for the period of 1950-2010 (Figure 1a) shows a significant decreasing trend; the reduction of $15 \%$ is significant at 99\% confidence level from a Mann-Kendall test. In addition, a correlation between the de-trended MT RH and MD frequency indicates that their association strengthened since mid-1990s, and significant above $95 \%$ confidence level from a two-tailed Student's t-test (Figure $1 \mathrm{~b}$ ); the correlation between the corresponding raw time series is much higher, as can be expected owing to the similar trend (a) trends in depression frequency and MT Rh

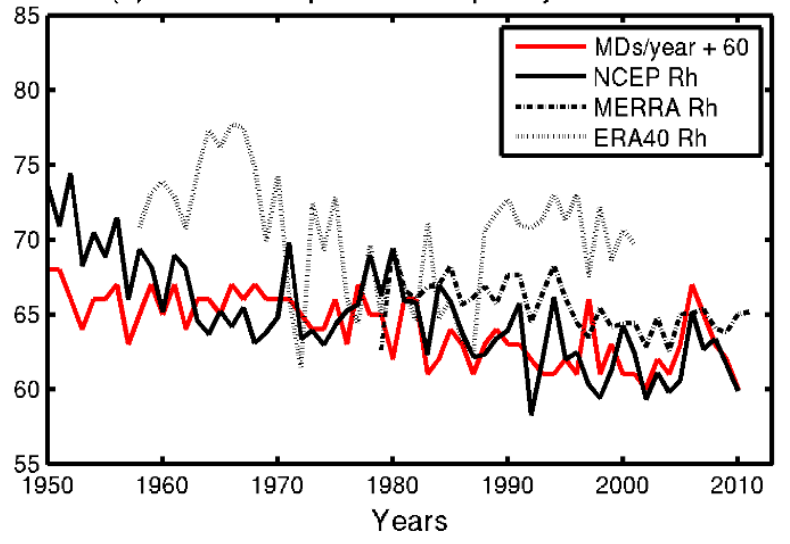

(b) 21 year window running correlation

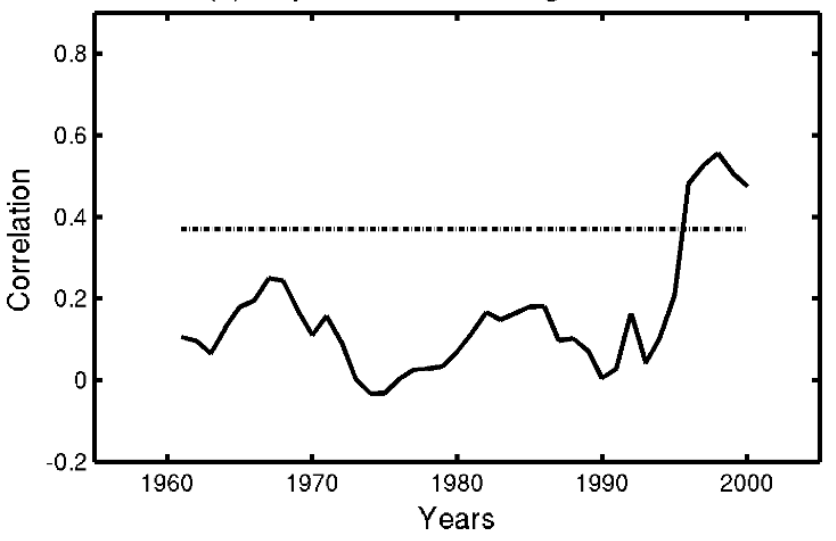

Figure 1 | Trends in depression frequency and MT RH: (a) The red line shows the time series of no: of depression/year (no: depression/year added with a constant number 60 to fit the time series into $y$-axis limits) and JJAS mean mid-tropospheric relative humidity from NCEP, Merra and ERA40 reanalysis (black lines). (b) 21 year window running correlation between depression frequency and JJAS mid-tropospheric relative humidity.

in both the time series. Further, as the RH from any reanalysis dataset is a derived parameter, we confirm the results by carrying out above analysis by replacing the RH with MT specific humidity.

According to $\mathrm{Gray}^{21}$, a minimum threshold of $40 \%$ the MT RH is necessary for tropical cyclogenesis. Low MT humidity would lead to the entrainment of relatively dry environment air into the parcel and a reduction in up-draft parcel buoyancy. Thus, the decrease in the MT RH over the BoB region could be a plausible reason for the decrease in the MD frequency since 1950s, and more likely from the late 1970s.

However, Paltridge et al. ${ }^{27}$ and Dessler ${ }^{28}$ caution about the reliability of the slow variability in the MT humidity from the NCEP/NCAR reanalysis data. Indeed, the quality of the parameters from other reanalysis datasets may also not be entirely reliable owing to various reasons such as the sparsity of observed data and sensor changes, particularly a "shock" due the inclusion of satellite data since late 1980s in reanalysis. Therefore, to confirm our finding from the NCEP/NCAR RH datasets, we present in Figures 2.a-c, the spatial distribution of the trends in the MT RH over Indian region from NCEP/NCAR reanalysis (1950-2010), ERA-40 (1958-2002), and Modern Era Retrospective-Analysis for Research and Applications (MERRA, 1979-present), respectively. In Figure 2a, a decreasing trend in the NCEP/NCAR MT RH is seen over the whole Indian land mass, Arabian Sea and BoB. In ERA-40, we see (Figure 2b) such 


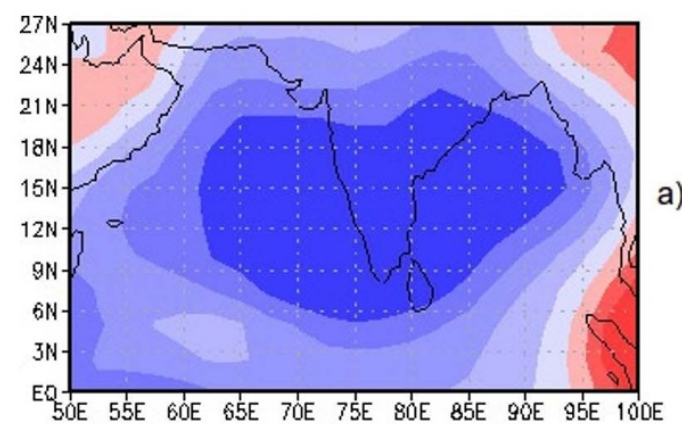

a)
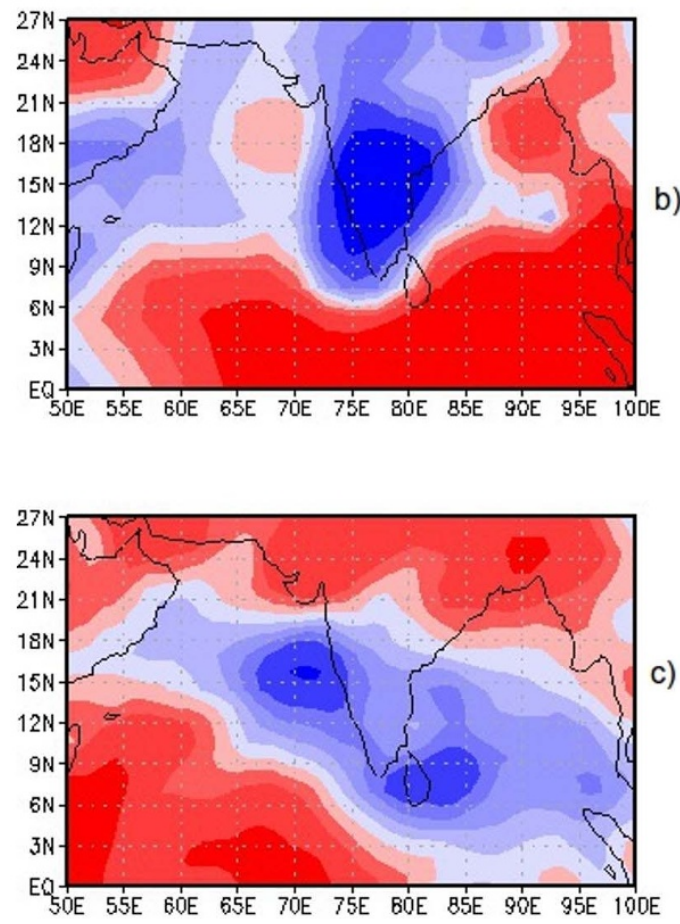

Figure 2 | Spatial map of trends in mid-tropospheric relative humidity in different re-analysis products. Top panel (a): NCEP reanalysis (19502010), middle panel (b): ERA-40(1958-2002), bottom panel (c): MERRA (1979-2010).

a significant decreasing trend over the Indian land mass, along with a relatively weaker negative trend over the $\mathrm{BoB}$ region abutting the east coast of the Indian peninsula. The MERRA MT RH also shows (Figure 2c) a significant trend in the southern region, particularly south of $20^{\circ} \mathrm{N}$. We can conclude from Figure 2 that the decreasing trend off the coast of India south of $20^{\circ} \mathrm{N}$ is more or less a common feature among all the three data sets. This qualitative agreement among the various MT RH datasets gives us confidence about the weakening trend in the MT humidity in this region, and therefore its role in weakening of the MDs therein.

Spatial differences in the decreasing frequency of MDs. In Figures 3(1a,1b,2a,2b), for (a) 1950-1979 and (b) 1980-2009 periods, we show the observed tracks of $\mathrm{MD}^{29}$ having genesis (1) south of $20^{\circ} \mathrm{N}$ and (2) north of $20^{\circ} \mathrm{N}$., respectively, The number of depressions formed south (north) of $20^{\circ} \mathrm{N}$ during the periods 19501979 and $1980-2009$ is 105 (53) and 43 (38), respectively. The decrease in the MD frequency is $59 \%$ (28\%) for the genesis region south (north) of $20^{\circ} \mathrm{N}$. Thus, though the decrease in number of depressions is seen all over the $\mathrm{BoB}$, the maximum contribution comes from the south of $20^{\circ} \mathrm{N}$.
This finding collates well with the finding that the MT RH has weakened in the recent decades particularly south of $20^{\circ} \mathrm{N}$.

Experiments with axi-symmetric tropical cyclone model. We now present results from the three numerical experiments we carried out to ascertain the role of the MT RH in the BoB in weakening the MDs. The first experiment, hereafter referred to as the control (CTRL) run, is to simulate a MD with the mean monsoon month conditions of Calcutta, on the BoB, we further perform two sensitivity experiments by reducing the MT RH by $5 \%$ and $10 \%$, respectively. The experiments are referred to as EXP-5\% and EXP-10\%, respectively. The RH profiles used for the experiments are shown in Figure $4 \mathrm{a}$.

The time variation of the simulated Central Surface Pressure (CSP) from all the experiments is presented in the Figure 4b. After 40 hours (h) CSP starts dropping in all the three cases, but with a slower rate for EXP-10\% compared to the CTRL experiment and EXP-5\%. Up to $80 \mathrm{~h}$ both the CTRL run and EXP-5\% show similar rate of CSP fall, but later the EXP-5\% demonstrates a relatively slower rate of decrease in CSP and stabilizes at $150 \mathrm{~h}$. At the mature (at $200 \mathrm{~h}$ ) stage, when the CSP reaches a more or less steady minimum value, the difference in the simulated CSP between CTRL and EXP$5 \%$ (EXP-10\%) runs is $4(7) \mathrm{hPa}$.

The time-radius cross sections of convective rainfall for these experiments are presented in Figure 5. In all the three cases, convective rain starts to occur just after $40 \mathrm{~h}$. In the CTRL run, rainfall of $20 \mathrm{~cm}$ /day and above is noticed in the mature stage, which is in good agreement with the observed rainfall for a typical $\mathrm{MD}^{1}$. After around $140 \mathrm{~h}$, a significant amount of convective rainfall occurs towards the center of the system. On the other hand, while the convective rain starts in EXP-5\% and EXP-10\% at the same time as in CTRL run, the intensity in these cases, however, is much weaker. Also, only just about $5 \sim 10 \mathrm{~cm} /$ day rain occurs towards the center of the system in case of EXP-5\% and negligible amount of rain occurs towards the center in the case of EXP-10\%.

The radial distributions of the simulated Cloud Base Mass Flux (CBMF) are shown in the Figure 6. It can be seen that the convective clouds started developing at 40 hours in all the cases. This corresponds to the initial time of developing stage of the system, as can be conjectured from the time variation of CSP from the Figure $4 \mathrm{~b}$. The maximum simulated CBMF at this stage is typically around 100$200 \mathrm{~g} / \mathrm{m}^{2} / \mathrm{s}$, and located around $160 \mathrm{~km}$ radius. Higher amounts can be seen in CTRL run compared to the other two cases. The tropospheric heating due to the latent heat release associated with the convection enhances the pressure gradient, which in turn enhances the moisture convergence towards the center of the system. The tropospheric heating which is proportional to the mass flux ${ }^{30,31}$, determines the growth of the system. Hence in CTRL run, the larger tropospheric heating due to larger CBMF produces more moisture convergence towards the center and eventually causing a wide spread precipitation towards the center. At the mature stage, the maximum CBMF values in the CTRL run are seen towards the center of the system. In contrast, very little CBMF amount is simulated in the EXP-5\% and almost nil in the EXP-10\%.

Tangential winds reaching a maximum of $15 \mathrm{~m} / \mathrm{s}$ can be seen in case CTRL run. Whereas in EXP-5\% and in EXP-10\% maximum tangential wind speed is around 6-9 m/s, much below the typically observed MD wind speed ${ }^{1,7}$ of $15-20 \mathrm{~m} / \mathrm{s}$ (Figure S3).

The results are in agreement with theory; from theories of growth mechanism of tropical cyclogenesis, it is clear that convective heating is the most important mechanism for the growth of MD. High MT humidity values are essential for maintaining the updraft parcel buoyancy in case of entrainment ${ }^{21}$. Low MT humidity can lead to upper level cooling, due to the re-evaporation of cumulus induced condensation by which it suppresses the growth of the disturbances. In summary, weakened MT RH results in weakened CBMF during the developing stage, which further weakens through the mature 


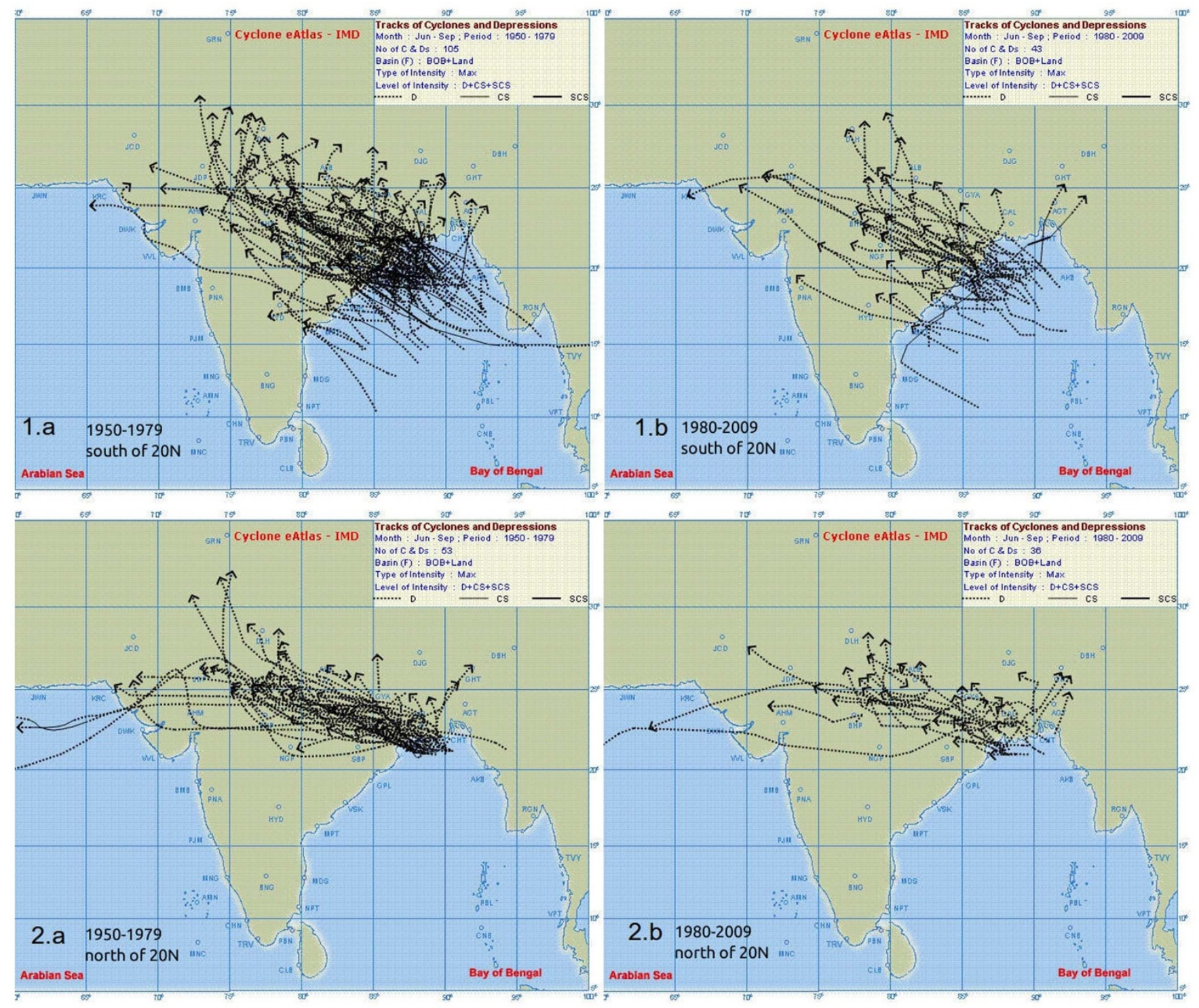

Figure 3 Tracks of the monsoon depressions from IMD cyclone e-atlas having genesis, 1.a) south of $20^{\circ} \mathrm{N}$ for the period $\left.1950-1979,1 . b\right)$ south of $20^{\circ} \mathrm{N}$ for the period $\left.1980-2009,2 . a\right)$ north of $20^{\circ} \mathrm{N}$ for the period $1950-1979$, and 2.b) north of $20^{\circ} \mathrm{N}$ for the period $1980-2009$. The figures, and the relevant statistics, have been generated using the online Cyclone eAtlas of the India Meteorological Department $<$ http://www.rmcchennaieatlas. tn.nic.in $>$.

stage. All this will eventually not allow the initial incipient disturbances to grow beyond a low pressure system.

\section{Discussion}

We find that, notwithstanding an increasing trend of SST in the BoB since 1950s, the MD frequency in the Bay of Bengal has continuously fallen. The fall in the frequency is statistically significant since late 1970s. The percentage decrease in the frequency of depression is seen to be more to the south of $20^{\circ} \mathrm{N}$, with a $59 \%$ fall as compared to the $28 \%$ of decadal weakening of the MD frequency north of $20^{\circ} \mathrm{N}$. Our results suggest that a concurrent weakening trend in the MT RH over the Bay of Bengal south of $20^{\circ} \mathrm{N}$ is a major factor in reducing the MD frequency. Further, results from our sensitivity tests carried out using an axi-symmetric model strongly support the hypothesis that a weakened MT humidity results in inhibition of the amplification of the initial tropical cyclonic perturbations.

Our results may be subject to the limitations associated with the reanalysis data quality, particularly that of the MT RH; however, qualitatively similar result from all the three reanalysis datasets alleviates this concern substantially.
Interestingly, it has been documented that large-scale summer monsoon circulation in recent decades has weakened ${ }^{22,32-35}$. To explore the relevance, we carried out an analysis of decadal changes in low level moisture convergence over the Indian region and surrounding ocean. The result (Figure not shown) also indicates a general weakening of moisture convergence over the region. This indicates that the falling frequency of the MDs may be due to weakening Indian summer monsoon circulation. A question that naturally arises is whether the observed global warming in the last $3 \sim 4$ decades has any role to play in the reduction of MDs in the Bay of Bengal. In this context, it is relevant to note that, as per a recent Special Report of the Intergovernmental Panel on Climate Change ${ }^{36}$, it is not yet clear whether extreme events are expected to increase due to global warming. In addition, studies such as Matsuura et al. ${ }^{37}$ indicate that interdecadal changes in tropical synoptic disturbance activity may be also due to natural decadal variability such as the in situ long-term variations in atmosphere-ocean coupling phenomena. Further, there is no general agreement among studies based on the dynamical models whether monsoons will strengthen or weaken due to global warming. For example, Krishnan et al. ${ }^{35}$ and Rajendran 

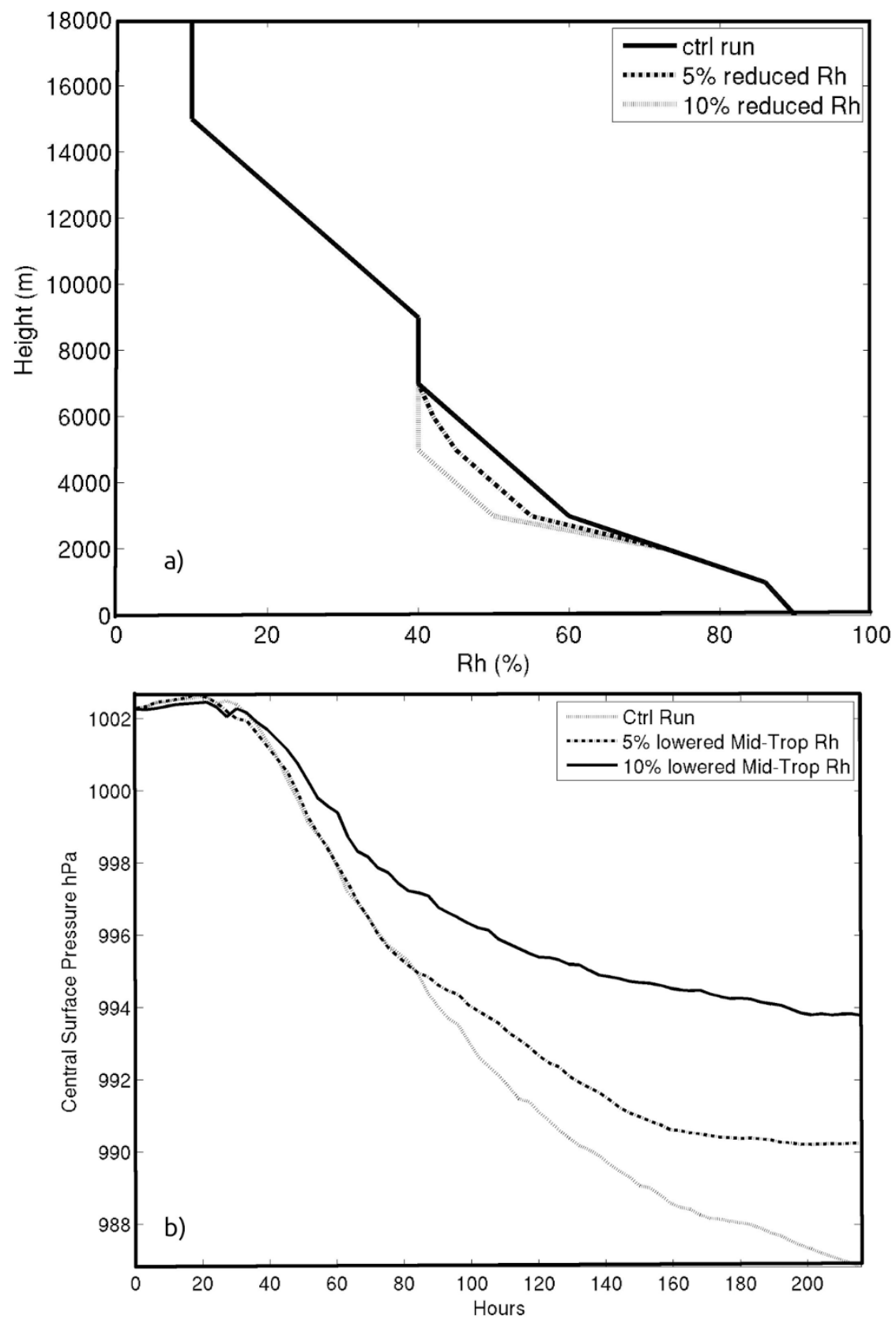

Figure 4 | Top panel (a): Relative humidity profiles used for the axi-symmetric model experiment. Bottom panel (b): Time variation of Central Surface Pressure (CSP).

et al. ${ }^{38}$, using some high resolution model projections of AR4 vintage, suggest an association between the global warming and monsoon weakening. On the other hand, several AR4 model projections (e.g. Kripalani et al. ${ }^{39}$ ) indicate a possibility that monsoon rainfall may increase with increased global warming. More recently, Jourdain et al. ${ }^{40}$ document that projections from about 11 models of CMIP5 vintage, which are able to simulate the Indian summer Monsoon features and teleconnections realistically, indicate that the monsoon rainfall may intensify due to global warming. Further, in addition to the in situ conditions in the Bay of Bengal, remote, decadal changes, such as that in land surface temperature over Tibetan plateau may also affect the intensity of Indian summer Monsoon ${ }^{41-43}$, there by leading to changes in the in-situ GraySikka conditions. Such issues are beyond the scope current study, and needs further research, including an analysis of multi-model climate change projections.

\section{Methods}

Data. We use the MD tracks and frequency data from the "Cyclone eAtlas - IMD" published by the India Meteorological Department ${ }^{29}$ for the 1950-2010 period. For the same period, we also use the Hadley Centre Sea Ice and Sea Surface Temperature data set (HadISST) ${ }^{44}$, and wind and the relative-humidity data mainly from the NCEP/NCAR Reanalysis data set ${ }^{45}$. In addition, we use the ERA-40 datasets ${ }^{46}$ for the 1958-2002 period, and MERRA ${ }^{47}$ (Modern Era-Retrospective Analysis For Research And Applications) for the period 1979-2010 for verification.

A spatial map of frequency of formation of depressions during JJAS season for the period 1950-2010 (figure S1.a) indicates ${ }^{29}$ that most MDs in the BoB occur in the region bound by $80^{\circ} \mathrm{E}-90^{\circ} \mathrm{E}$ and $15^{\circ} \mathrm{N}-25^{\circ} \mathrm{N}$. Therefore, we average the various physical parameters over this region to obtain the corresponding representative Indices for further analysis. The individual seasonal anomalies of various parameters have been obtained by subtracting the long term seasonal climatology from the respective individual seasonal value of the parameter that year.

Model. We performed sensitivity experiments using a nineteen-level axi-symmetric mode ${ }^{48,49}$ which uses a simplified variant of the Arakawa-Schubert convective parameterization scheme, after Grell ${ }^{50,51}$. The model and its variants have been 

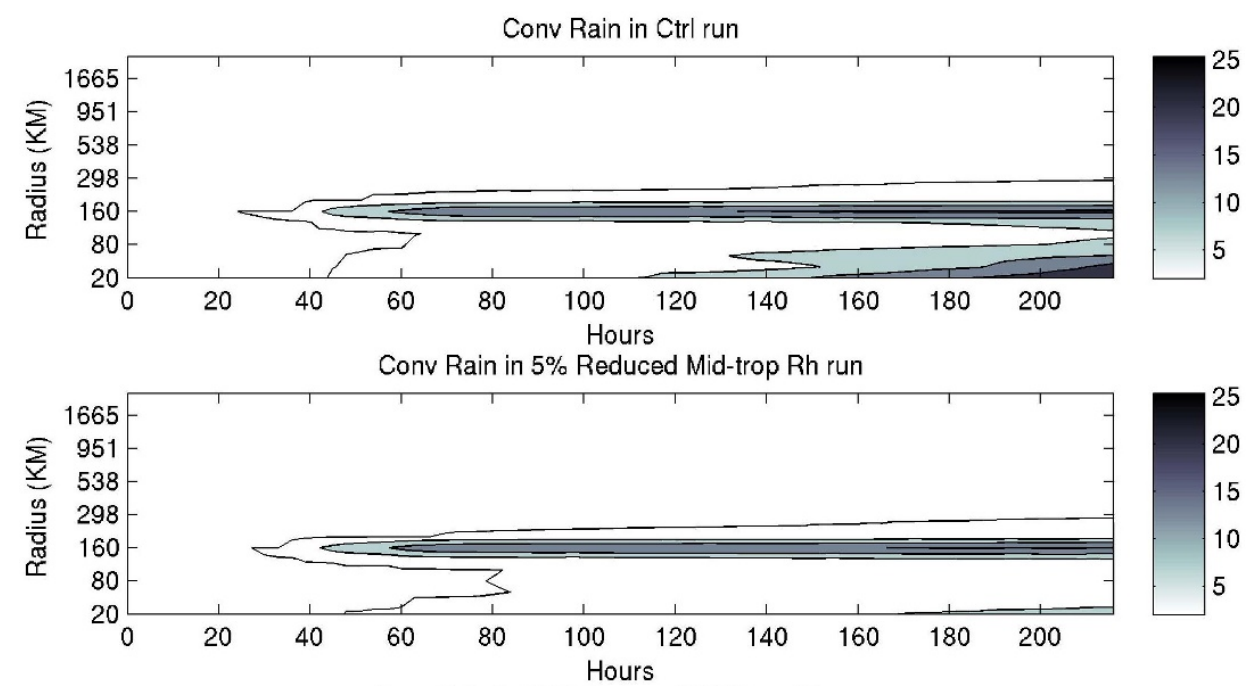

Conv Rain in $10 \%$ Reduced Mid-trop Rh run

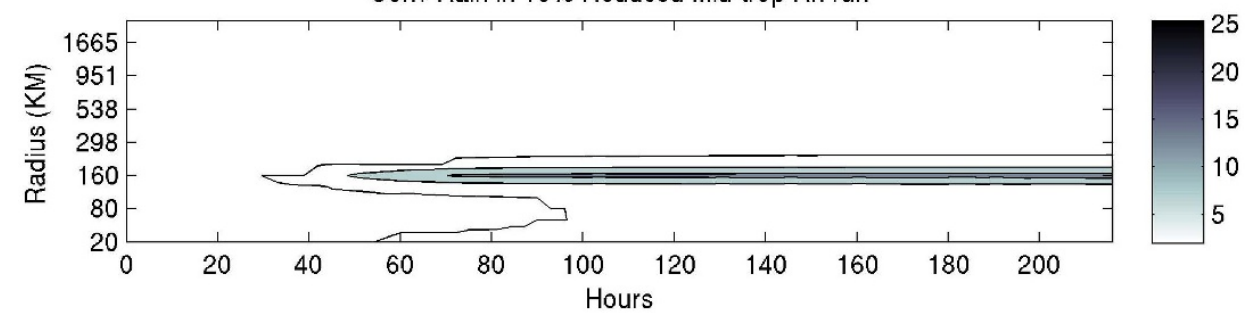

Figure 5 Time-radius cross section of convective rain fall (in $\mathrm{cm} /$ day). The top panel shows CTRL run, middle one shows EXP-5\% and bottom one shows EXP-10\%.
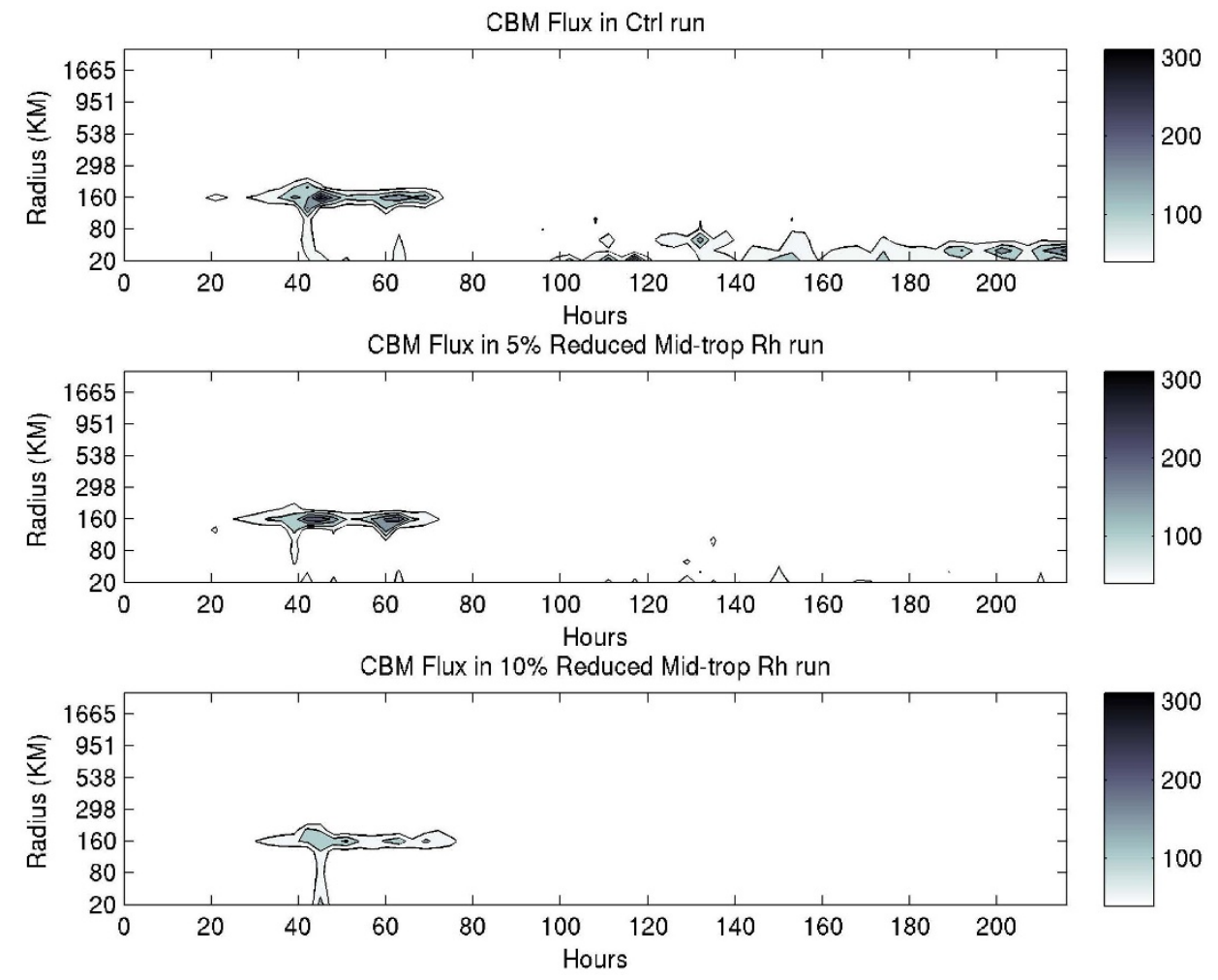

Figure 6 | Time-radius section of cloud base mass flux $\left(\mathrm{g} / \mathrm{m}^{2} / \mathrm{s}\right)$. The top panel shows CTRL run, middle one shows EXP-5\% and bottom one shows EXP$10 \%$. 
extensively used to study the evolution of the tropical cyclogenesis in various tropical oceans, including $\mathrm{BoB}^{48,49,52}$.

The air-density is assumed to be a function of height only. Planetary boundary layer have been parameterized in the model using the Deardorff $f^{53}$ boundary layer scheme. Vertical velocity $\mathrm{w}$ is taken as zero at $\mathrm{z}=0$ and $\mathrm{z}=\mathrm{z}_{\max }$ i.e., at the bottom and top of the model atmosphere $\left(\mathrm{z}_{\max }=19 \mathrm{~km}\right)$.

Radius of the outer periphery of the computational domain is taken as $2500 \mathrm{~km}$ in this model. The domain of such a large size is used to reduce the influence of the lateral boundary on the storm structure at the center. The model atmosphere has been divided into 18 vertical layers between $0-19 \mathrm{~km}$, with the 19 levels designated at 0,1 , $2,3, \ldots, \& 19 \mathrm{~km}$ heights. The horizontal computational domain is divided into 21 concentric telescopic rings, with a horizontal resolution of $20 \mathrm{~km}$ within the $100 \mathrm{~km}$, beyond which the resolution becomes coarse as one moves away.

The initial perturbation is imposed via potential temperature and is given by

$$
\theta^{\prime}(r, z)=0.24\left[\cos \frac{\pi}{r_{0}} r+1\right] \sin \left[\frac{\pi}{z_{t}} z\right]
$$

For $\mathrm{r}<\mathrm{r}_{0}(=300 \mathrm{~km}) . \mathrm{z}_{\mathrm{t}}=19 \mathrm{~km}$.

Further details of the model can be obtained from Rao \& Ashok ${ }^{48,49}$. The mean vertical distribution of temperature and $\mathrm{RH}$ of the month June for Calcutta have been adopted as the initial conditions. However, the model sensitivity to the MT-RH was more or less similar even after we used a few available sounding profiles from the south-eastern stations such as Machilipatnam, Bhubaneswar and Visakhapatnam, which are affected by the MDs. All the experiments were conducted with a constant SST of $301 \mathrm{~K}$. The integration was carried out for 240 hours in all the cases.

1. Sikka, D. R. Some aspects of the life history, structure and movement of monsoon depressions. Pure and Applied Geophysics 115, 1501-1529 (1977).

2. Rajeevan, M., De, U. S. \& Prasad, R. K. Decadal variation of sea surface temperatures, cloudiness and monsoon depressions in the north Indian ocean. Current Science 79, 283-285 (2000).

3. Iyer, V. Typhoons of the Pacific Oceans and South China Sea. Indian Meteorological Department Scientific Notes (1931)

4. Koteswaram, P. \& Rao, N. Formation and structure of Indian summer monsoon depressions. Australian Meteorological Magazine 41, 2-75 (1963).

5. Krishnamurti, T. N., Molinari, J., Pan, H. \& Wong, V. Downstream amplification and Formation of Monsoon disturbances. Monthly Weather Review 105 1281-1297 (1977)

6. Saha, K., Sanders, F. \& Shukla, J. Westward propagating predecessors of monsoon depressions. Monthly Weather Review 109 (1981).

7. Godbole, R. V. The composite structure of the monsoon depression. Tellus 29, 25-40 (1977).

8. Stano, G. \& Krishnamurti, T. Hydrometeor structure of a composite monsoon depression using the TRMM radar. Tellus A (2002).

9. Sikka, D. Some aspects of the large scale fluctuations of summer monsoon rainfall over India in relation to fluctuations in the planetary and regional scale circulation parameters. Proceedings of the Indian Academy of Sciences-Earth and Planetary Sciences 89, 179-195 (1980).

10. Mooley, D. A. \& Shukla, J. Main features of the westward-moving low pressure systems which form over the Indian region during the summer monsoon season and their relation to the monsoon rainfall. Mausam 40, 137-152 (1989).

11. Jadhav, S. Summer monsoon low pressure systems over the Indian region and their relationship with the sub-divisional rainfall. Mausam 53, 177-186 (2002).

12. Krishnamurthy, V. \& Ajayamohan, R. S. Composite Structure of Monsoon Low Pressure Systems and Its Relation to Indian Rainfall. Journal of Climate 23, 4285-4305 (2010)

13. Mohapatra, M. \& Mohanty, U. C. Some characteristics of low pressure systems and summer monsoon rainfall over Orissa. Current science 87, 1245-1255 (1999).

14. Rao, G. Occurrence of heavy rainfall around the confluence line in monsoon disturbances and its importance in causing floods. Proceedings of the Indian Academy of Sciences-Earth and Planetary Sciences 87-94 (2001).

15. Patwardhan, S. K. \& Bhalme, H. N. A study of cyclonic disturbances over India and the adjacent ocean. International journal of climatology 21, 527-534 (2001).

16. Mandke, S. \& Bhide, U. V. A study of decreasing storm frequency over Bay of Bengal. The Journal of Indian Geophysical Union 7, 53-58 (2003).

17. Jadhav, S. K. \& Munot, A. A. Warming SST of Bay of Bengal and decrease in formation of cyclonic disturbances over the Indian region during southwest monsoon season. Theoretical and applied climatology 96, 327-336 (2009).

18. Rajendra Kumar, J. \& Dash, S. K. Interdecadal variations of characteristics of monsoon disturbances and their epochal relationships with rainfall and other tropical features. International journal of climatology 21, 759-771 (2001).

19. Chan, J. C. L. \& Liu, K. S. Global warming and western North Pacific typhoon activity from an observational perspective. Journal of Climate 17, 4590-4602 (2004)

20. Webster, P. J., Holland, G. J., Curry, J. A. \& Chang, H. R. Changes in tropical cyclone number, duration, and intensity in a warming environment. Science 309, 1844-1846 (2005).

21. Gray, W. M. Tropical cyclone genesis. (Department of Atmospheric Science, Colorado State University, 1975).
22. Rao, B. R. S., Rao, D. V. B. \& Rao, V. B. Decreasing trend in the strength of Tropical Easterly Jet during the Asian summer monsoon season and the number of tropical cyclonic systems over Bay of Bengal. Geophysical Research Letters 31, n/a-n/a (2004).

23. Keshavamurty, R. N., Asnani, G. C., Pillai, P. V. \& Das, S. K. Some studies of the growth of monsoon disturbances. Journal of Earth System Science 87, 61-75 (1978).

24. Shukla, J. CISK-barotropic-baroclinic instability and the growth of monsoondepressions. Journal of the Atmospheric Sciences 35, 495-508 (1978).

25. Mishra, S. K. \& Salvekar, P. S. Role of baroclinic instability in the development of monsoon disturbances. Journal of the Atmospheric Sciences (1980).

26. Ramesh Kumar, M. R. \& Sankar, S. Impact of global warming on cyclonic storms over north Indian Ocean. 39, 516-520 (2010).

27. Paltridge, G., Arking, A. \& Pook, M. Trends in middle-and upper-level tropospheric humidity from NCEP reanalysis data. Theoretical and Applied Climatology 98, 351-359 (2009).

28. Dessler, A. E. \& Davis, S. M. Trends in tropospheric humidity from reanalysis systems. Journal of Geophysical Research 115, D19127 (2010).

29. IMD. Tracks of cyclones and depressions in the Bay of Bengal and Arabian Sea 1891-2012, Electronic version, June 2008. (2012).

30. Charney, J. \& Eliassen, A. On the growth of the hurricane depression. Journal of the Atmospheric Sciences 21, 68-75 (1964).

31. Ooyama, K. Numerical simulation of the life cycle of tropical cyclones. Journal of the Atmospheric Sciences 26, 3-40 (1969).

32. Joseph, P. V. \& Simon, A. Weakening trend of the southwest monsoon current through peninsular India from 1950 to the present. Curr. Sci 89, 687-694 (2005).

33. Sathiyamoorthy, V. Large scale reduction in the size of the Tropical Easterly Jet. Geophysical Research Letters 32, n/a-n/a (2005).

34. Ramesh Kumar, M. R., Krishnan, R., Sankar, S., Unnikrishnan, A. S. \& Pai, D. S. Increasing Trend of "Break-Monsoon" Conditions Over India-Role of OceanAtmosphere Processes in the Indian Ocean. Geoscience and Remote Sensing Letters, IEEE 6, 332-336 (2009).

35. Krishnan, R. et al. Will the South Asian monsoon overturning circulation stabilize any further? Climate Dynamics 40, 187-211 (2012).

36. IPCC. Managing the risks of extreme events and disasters to advance climate change adaptation: Special report of the intergovernmental panel on climate change. (2012).

37. Matsuura, T., Yumoto, M. \& Iizuka, S. A mechanism of interdecadal variability of tropical cyclone activity over the western North Pacific. Climate Dynamics 21, 105-117 (2003)

38. Rajendran, K., Kitoh, A., Srinivasan, J., Mizuta, R. \& Krishnan, R. Monsoon circulation interaction with Western Ghats orography under changing climate. Theoretical and Applied Climatology 110, 555-571 (2012).

39. Kripalani, R. H., Oh, J. H. \& Chaudhari, H. S. Response of the East Asian summer monsoon to doubled atmospheric $\mathrm{CO}_{2}$ : Coupled climate model simulations and projections under IPCC AR4. Theoretical and Applied Climatology 87, 1-28 (2007).

40. Jourdain, N. et al. The Indo-Australian monsoon and its relationship to ENSO and IOD in reanalysis data and the CMIP3/CMIP5 simulations. Climate Dynamics 1-30 (2013). doi:10.1007/s00382-013-1676-1.

41. Sato, T. \& Kimura, F. How Does the Tibetan Plateau Affect the Transition of Indian Monsoon Rainfall? Monthly Weather Review 135, 2006-2015 (2007).

42. Rajagopalan, B. \& Molnar, P. Signatures of Tibetan Plateau heating on Indian summer monsoon rainfall variability. Journal of Geophysical Research: Atmospheres 118, 1170-1178 (2013).

43. Wu, G. et al. Thermal controls on the Asian summer monsoon. Sci. Rep. 2, 404 (2012).

44. Rayner, N. A. et al. Global analyses of sea surface temperature, sea ice, and night marine air temperature since the late nineteenth century. J. Geophys. Res. 108, 4407 (2003).

45. Kalnay, E. et al. The NCEP/NCAR 40-year reanalysis project. Bulletin of the American Meteorological Society 77, 437-471 (1996).

46. Uppala, S. M. et al. The ERA-40 re-analysis. Quarterly Journal of the Royal Meteorological Society 131, 2961-3012 (2005).

47. Rienecker, M. M. et al. MERRA: NASA's Modern-Era Retrospective Analysis for Research and Applications. Journal of Climate 24, 3624-3648 (2011).

48. Bhaskar Rao, D. V. \& Ashok, K. Simulation of Tropical Cyclone Circulation Over the Bay of Bengal Using the Arakawa-Schubert Cumulus Parameterization. Part II: Some Sensitivity Experiments. Pure and Applied Geophysics 158, 1017-1046 (2001).

49. Bhaskar Rao, D. V. \& Ashok, K. Simulation of Tropical Cyclone Circulation over Bay of Bengal Using the Arakawa-Schubert Cumulus Parametrization. Part I -Description of the Model, Initial Data and Results of the Control Experiment. Pure and Applied Geophysics 156, 525-542 (1999).

50. Grell, G. A. Prognostic evaluation of assumptions used by cumulus parameterizations. Monthly Weather Review 121, 764-787 (1993).

51. Grell, G. A., Dudhia, J., Stauffer, D. R. \& others. A description of the fifthgeneration Penn State/NCAR mesoscale model (MM5). (1994).

52. Bhaskar Rao, D. V. Numerical simulation of tropical-cyclone circulation using Arakawa-Schubert cumulus parameterization. Il Nuovo Cimento C 10, 677-696 (1987). 
53. Deardorff, J. W. Parameterization of the Planetary Boundary layer for Use in General Circulation Models 1. Monthly Weather Review 100, 93-106 (1972).

54. Ashok, K., Soman, M. K. \& Satyan, V. Simulation of Monsoon Disturbances in a GCM. Pure Appl. Geophys. 157, 1509-1539 (2000).

\section{Acknowledgements}

We thank Prof. G. S. Bhat and Prof. R.N. Keshava Murthy for their insightful comments. We acknowledge Indian Meteorology Department, Chennai for the permission to use Cyclone eAtlas in this study. We thank the Director, IITM for his support.

\section{Author contributions}

A.G.P. did the analysis and wrote the manuscript with significant inputs from K.A. K.A. conceived the idea and co-wrote the manuscript. D.V.B.R. provided and helped in setting up the axi-symmetric model. All authors discussed the results.

\section{Additional information}

Supplementary information accompanies this paper at http://www.nature.com/ scientificreports

Competing financial interests: The authors declare no competing financial interests. How to cite this article: Prajeesh, A.G., Ashok, K. \& Rao, D.V.B. Falling monsoon depression frequency: A Gray-Sikka conditions perspective. Sci. Rep. 3, 2989; DOI:10.1038/ srep02989 (2013)

(c) (1) (2) This work is licensed under a Creative Commons Attributionvisit http://creativecommons.org/licenses/by-nc-sa/3.0 